\title{
Truly Random Degradable Vinyl Copolymers via Photocontrolled Radical Ring-Opening Cascade Copolymerization
}

\author{
Wenqi Wang, ${ }^{[\mathrm{a}]}$ Zefeng Zhou,${ }^{[\mathrm{a}]}$ Xuanting Tang, ${ }^{[\mathrm{a}]}$ Stephanie Moran, ${ }^{[\mathrm{a}]}$ Jing Jin, ${ }^{[\mathrm{a}]}$ Fredrik Haeffner,${ }^{[\mathrm{a}]}$ and \\ Jia Niu*[a] \\ [a] W. Wang, Z. Zhou, X. Tang, S. Moran, Dr. J. Jin, Dr. F. Haeffner, Prof. J. Niu \\ Department of Chemistry \\ Boston College \\ Chestnut Hill, Massachusetts 02467, United States \\ E-mail: jia.niu@bc.edu
}

Supporting information for this article is given via a link at the end of the document

\begin{abstract}
Degradable vinyl polymers by radical ring-opening polymerization have become a promising solution to the challenges caused by the widespread use of non-degradable vinyl plastics. However, achieving even distribution of labile functional groups in the backbone of degradable vinyl polymers remains challenging. Herein, we report a photocatalytic approach to truly random degradable vinyl copolymers with tunable main-chain composition via radical ringopening cascade copolymerization (rROCCP). The rROCCP of the macrocyclic allylic sulfone and acrylates or acrylamides mediated by visible light at ambient temperature achieved near-unity reactivity ratios of both comonomers over the entire range of the comonomer compositions and afforded truly random vinyl copolymers with degradable units evenly distributed in the polymer backbone. Experimental and computational evidence revealed an unusual reversible inhibition of chain propagation by in situ generated sulfur dioxide, which was successfully overcome by reducing the solubility of sulfur dioxide in the reaction mixture. This study provided a powerful approach to truly random degradable vinyl copolymers with tunable main-chain labile functionalities and comparable thermal and mechanical properties to traditional non-degradable vinyl polymers.
\end{abstract}

\section{Introduction}

Vinyl polymers have been widely used in an array of applications including packaging, structural materials, synthetic fibers, coating, absorbent, and many others. While the all-carbon backbone makes vinyl polymers highly robust materials, it has also created significant challenges in their degradation, leading to critical environmental issues caused by plastic accumulation in landfills and the ocean. ${ }^{1-2}$ Therefore, significant efforts have been made in recent years to develop innovative synthetic polymers that possess thermal and mechanical properties comparable to the original, nondegradable vinyl polymers and can undergo facile degradation at the end of their life cycle. ${ }^{3-4}$ Among various approaches to degradable vinyl polymers, radical ring-opening polymerization ( $\mathrm{rROP}$ ) is of great interest. Attractive features of rROP include its abilities to incorporate labile functional groups (e.g. esters, thioesters, disulfide, etc.) into the polymer main chain $^{5-7}$ and interface with a plethora of reversible deactivation radical polymerization (RDRP) techniques for the synthesis of polymers with complex and defined macromolecular architectures. $^{8}$

Since the advent of rROP, various cyclic monomers have been successfully developed for the synthesis of degradable vinyl (co)polymers. ${ }^{6}$ As a representative class of rROP monomer, cyclic ketene acetals (CKAs) have been extensively investigated since 1980 s. $^{9}$ Despite recent progress made by Dove, ${ }^{10-14}$ Nicolas, ${ }^{15-20}$ and Sumerlin, ${ }^{21-22}$ unfavorable reactivity ratios in the copolymerization of CKA with other vinyl monomers often lead to gradient or tapered compositions of the resultant copolymer. ${ }^{23}$ The gradient composition in turn resulted in highly dispersed degradation products and large non-degradable fragments, as part of the copolymer lacked main-chain degradable units. Although new cyclic monomer classes including macrocyclic allylic sulfide (MAS) ${ }^{24-27}$ and dibenzo[c,e]oxepane-5-thione $(\mathrm{DOT})^{28-30}$ (Figure 1A) have demonstrated promising properties, truly random copolymerization of these cyclic monomers with acrylates or acrylamides remains challenging. In 2018, we reported an approach to the radical ring-opening cascade polymerization of allylic sulfone macrocyclic monomers. ${ }^{31}$ The radical cascade reaction of macrocyclic allylic sulfone could extrude sulfur dioxide $\left(\mathrm{SO}_{2}\right)$ and generate a secondary alkyl radical capable of controlled chain propagation. ${ }^{32}$ However, copolymerization of the macrocyclic allylic sulfone and acrylates exhibited unfavorable reactivity ratios at high temperatures. Therefore, it is essential to develop a method that provides access to truly random copolymers with tunable compositions and evenly distributed main-chain functional groups.

Recent studies suggest that temperature has a strong influence on the reactivity ratios in the radical copolymerization of cyclic and acyclic vinyl comonomers. ${ }^{6}$ We reasoned that performing the copolymerization at lower temperatures would provide a key opportunity to modulate the reactivity ratios of vinyl comonomers. Therefore, we turned our attention to light-mediated polymerization techniques, as recent works have demonstrated that they are versatile tools to mediate controlled polymerization following radical, ${ }^{33-41}$ cationic, ${ }^{42-46}$ and metathesis pathways ${ }^{47-49}$ at ambient temperature (Figure 1B)..$^{50}$ In particular, we envisioned that the photoinduced electron/energy transfer-reversible addition/fragmentation chain transfer (PET-RAFT) polymerization developed by Boyer and coworkers ${ }^{51-56}$ could be employed to mediate radical ring-opening cascade copolymerization $(\mathrm{rROCCP})^{57-58}$ of the macrocyclic allylic sulfone and acrylates or acrylamides (Figure 1C). Unlike the polymerization initiated by azobisisobutyronitrile (AIBN) that required high temperatures (80$100{ }^{\circ} \mathrm{C}$ ) to maintain a sufficiently high rate of propagation, PETRAFT can be performed at mild temperatures, thereby enabling favorable comonomer reactivity ratios in copolymerization. To the best of our knowledge, the photocontrolled rROCCP represents the first method that achieved truly random radical copolymerization of cyclic monomers and acrylic monomers over the entire range of comonomer compositions. 
A. Recent rROP developments:<smiles>C=C1OCCCCO1</smiles>

CKA

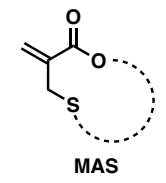

- Controlled homopolymerization is challenging

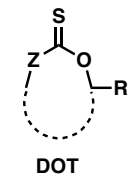

DOT

B. Photocontrolled polymerization of simple vinyl monomers:

C. This work: truly random degradable vinyl copolymers via photocontrolled rROCCP:

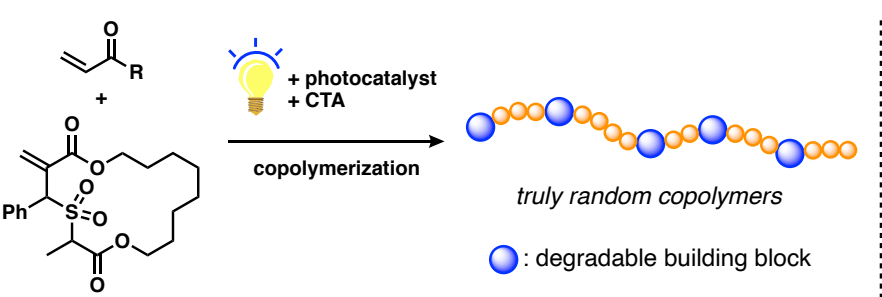

- Excellent control - Tunable copolymer composition - Switching "on" and "off" by light and $\mathrm{SO}_{2}$
Mechanistic insight into reversible $\mathrm{SO}_{2}$ inhibition:

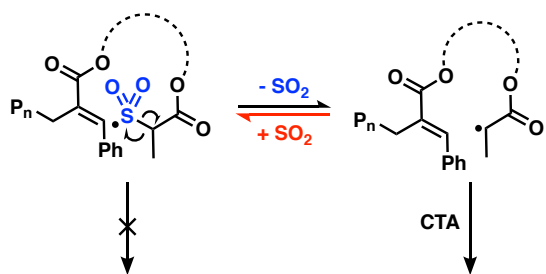

Propagation is inhibited

Figure 1. Truly random degradable vinyl copolymers via photocontrolled radical ring-opening cascade copolymerization (rROCCP).

\section{Results and Discussion}

\section{PET-RAFT Polymerization of Macrocyclic Allylic Sulfones}

Our investigation began by screening various wellestablished photocatalysts to mediate the photocontrolled homopolymerization of allylic sulfone macrocyclic monomer 1 under visible light irradiation (Table S1)..$^{51-55}$ We screened an array of photocatalysts, including fac-[lr(ppy) $\left.)_{3}\right], \mathrm{Ru}(\mathrm{bpy})_{3} \mathrm{Cl}_{2}$, ZnTPP, and Eosin Y, and identified fac-[Ir(ppy) $\left.)_{3}\right]$ as a promising photocatalyst for the reaction due to the excellent control over the polymerization when combined with CTA1. At a monomer/CTA ratio of $50: 1$, our initial attempt of the polymerization of macrocyclic allylic sulfone 1 mediated by fac-[Ir(ppy) 3$]$ and CTA1 under $450 \mathrm{~nm}$ light irradiation yielded P-1 with $M_{\mathrm{n}}{ }^{\text {(SEC) }}$ of 9.8 $\mathrm{kg} / \mathrm{mol}$ and $\emptyset$ of 1.11 (Table S2). Further examination of the reaction conditions found that optimal polymerization was achieved when the monomer concentration was at $0.2 \mathrm{M}$ in DMF and the catalyst loading reached 200 ppm (Table S3-S5). Polymerization of 1 at other monomer/CTA ratios of 25:1, 100:1, and 200:1 successfully yielded polymers with predictable $M_{\mathrm{n}}$ and low $\triangleq$, demonstrating excellent control over the polymerization (Table S6). Similarly, macrocyclic allylic sulfone 2 with a smaller ring size was also polymerized with good control under the same conditions (Table S7). It is noteworthy that no ring-retaining propagation of both allylic sulfone macrocyclic monomers 1 and 2 has been observed.

Following the exploration of reaction conditions, we examined the living characteristics of the polymerization. First, the kinetic analysis revealed that the polymerization of $\mathbf{1}$ deviated from first-order kinetics in the late stage (Figure S1). This observation was consistent with our previous results when the cascade polymerization of macrocyclic allylic sulfone was thermally initiated. ${ }^{31,59}$ Despite the kinetic anomaly, the polymerization of 1 still exhibited a linear increase of $M_{\mathrm{n}}$ with respect to the monomer conversion and remained low $D$ throughout the reaction, suggesting that control over the polymerization was well maintained even after the rate decreased in the late stage (Figure 2A). ${ }^{1} \mathrm{H}-\mathrm{NMR}$ analysis of P-1-6k $\left(M_{\mathrm{n}}\right.$ (SEC) $=6.4 \mathrm{~kg} / \mathrm{mol}, \ominus=1.07)$ confirmed the fidelity of the chain end groups (2.46 and $1.21 \mathrm{ppm}$ for $\alpha$-chain end and 4.81 and 3.36 ppm for $\omega$-chain end, Figure S2), an important indicator of controlled polymerization. Besides, the discrete oligomers of P-1$5 \mathbf{k}\left(M_{\mathrm{n}}^{(\mathrm{SEC})}=5.5 \mathrm{~kg} / \mathrm{mol}, \Theta=1.10\right)$ observed by matrix-assisted laser desorption/ionization time-of-flight (MALDI-TOF) mass spectrometry showed masses consistent with the predicted values of these oligomers with intact chain ends (Figure 2B). Furthermore, chain extension of the macroinitiator $\mathbf{P}-\mathbf{2}-\mathbf{4} \mathbf{k}\left(M_{\mathrm{n}}\right.$ (SEC) $=3.9 \mathrm{~kg} / \mathrm{mol}, \Theta=1.16$ ) by 1 exhibited a clear shift to the higher molecular weight region on the SEC chromatogram, suggesting the formation of a diblock copolymer P-2-b-P-1 $\left(M_{n}{ }^{(S E C)}=13.0\right.$ $\mathrm{kg} / \mathrm{mol}, \Xi=1.20$, Figure $2 \mathrm{C}$ ). Finally, the reaction exhibited excellent temporal control: chain propagation completely halted when the light was switched "off"; polymerization resumed efficiently after the light was switched back "on" (Figure 2D). Taken together, these results unambiguously supported that the PET-RAFT polymerization of macrocyclic allylic sulfones maintained an excellent control throughout the reaction despite the deviation from first-order kinetics at the late stage.

\section{Copolymerization of Macrocyclic Allylic Sulfones and Acrylates or Acrylamides}

Building upon the results of photocontrolled homopolymerization of macrocyclic allylic sulfones, we then investigated copolymerization of $\mathbf{1}$ and various acrylates or acrylamides (denoted hereafter as comonomer B). First, 1 was copolymerized with methyl acrylate (MA) at the feed composition of $f_{1}^{0}=0.05$, where $f_{1}^{0}$ is the molar fraction of 1 in the initial comonomer mixture, yielding copolymer P-1-co-MA with $M_{\mathrm{n}}$ (SEC) of $44.0 \mathrm{~kg} / \mathrm{mol}$ and $\Theta$ of 1.28 (Table 1 , entry 1 ). The propagation of both comonomers demonstrated first-order kinetics throughout the copolymerization (Figure $3 \mathrm{~A}$ ). The molecular weight also increased linearly with respect to the overall monomer conversion, which is defined by Eq 1:

conv. $=1-\frac{[\mathbf{1}(t)]+[B(t)]}{[\mathbf{1}(0)]+[B(0)]}$ 

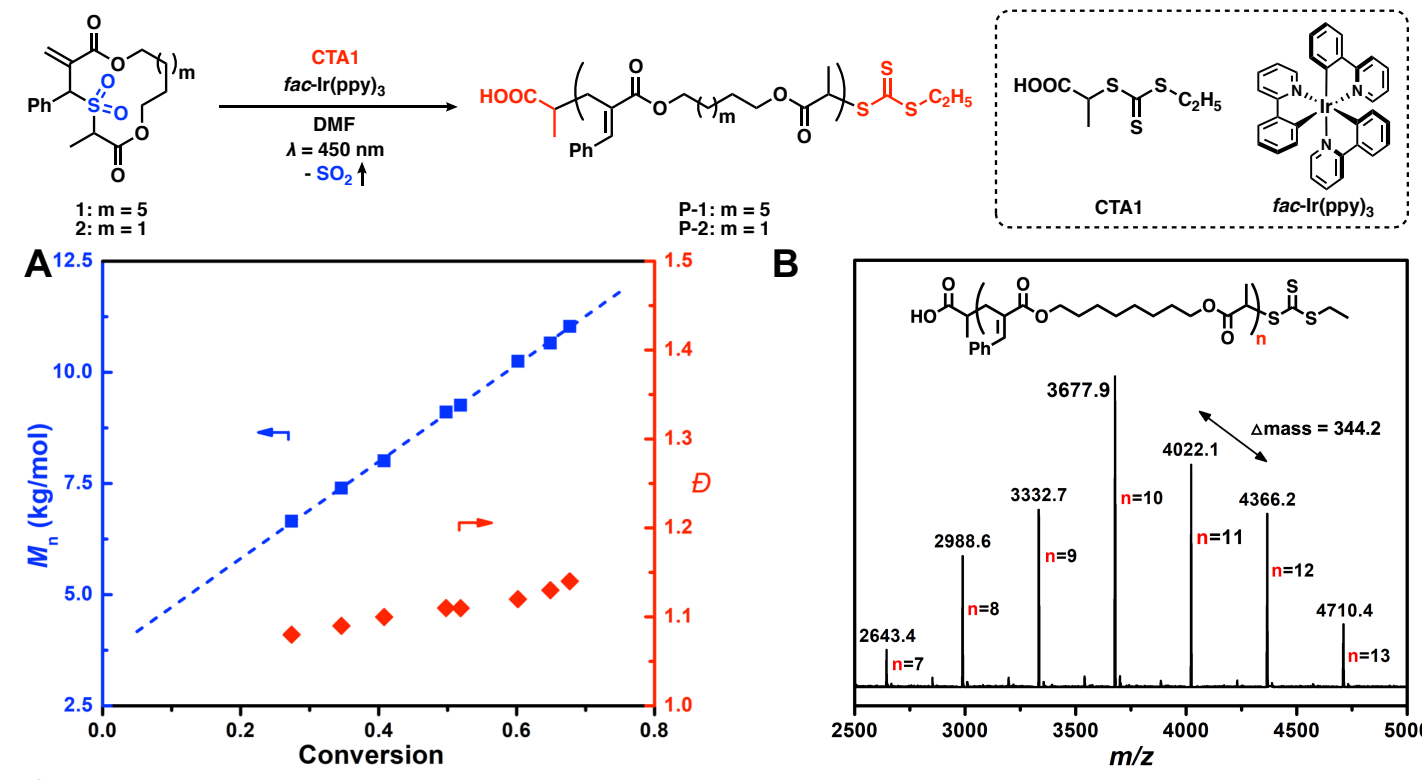

C

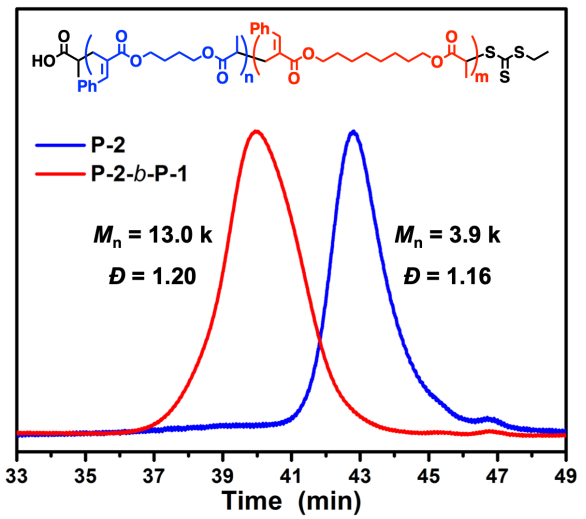

B
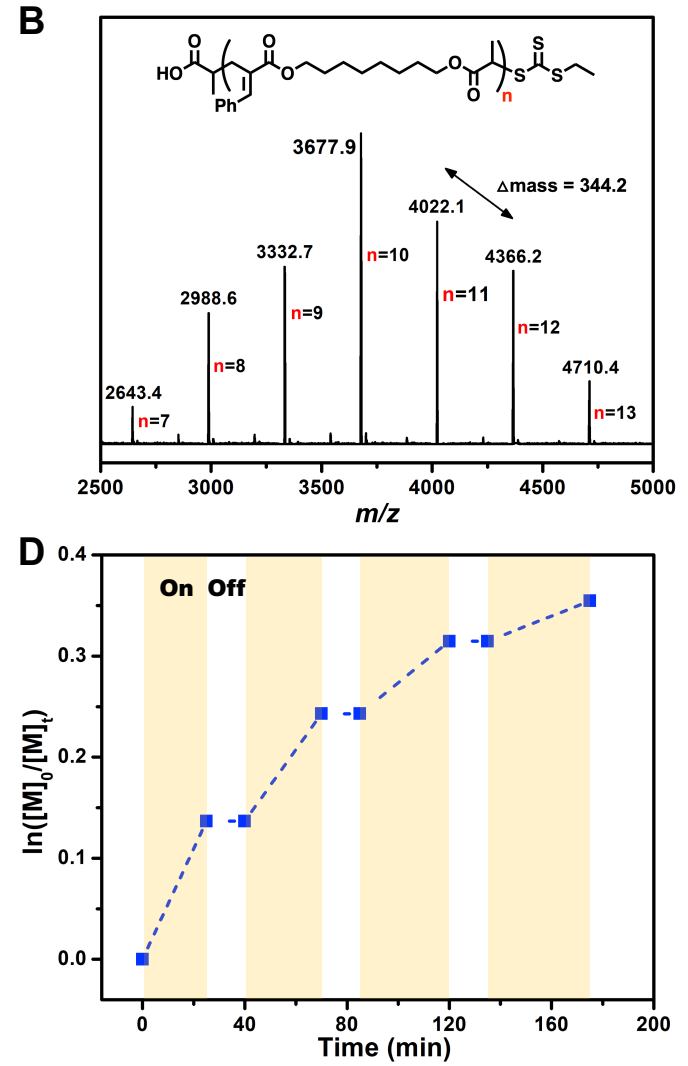

Figure 2. Analysis of the PET-RAFT polymerization of macrocyclic allylic sulfones. A) Plots of $M_{n}$ and $\doteq$ as a function of monomer conversion. B) MALDI-TOF analysis of P-1-5k. The spacing between these discrete oligomers was consistent with the expected mass of the repeating unit (344 $\mathrm{g} / \mathrm{mol})$. Each peak corresponds to a discrete oligomer that consists of the $\alpha$ - and $\omega$-chain end, the number of repeating units multiplied by its molar mass, and a sodium cation. C) SEC analysis of block copolymer P-2-b-P-1. D) $\ln \left([\mathrm{M}]_{0} /[\mathrm{M}]_{\mathrm{t}}\right)$ vs. reaction time with intermittent light exposure.

where $[1(\mathrm{t})]$ and $[\mathrm{B}(\mathrm{t})]$ are the respective instantaneous concentrations of 1 and comonomer $\mathrm{B}$ at time $t$, and $[1(0)]$ and $[B(0)]$ are the respective initial concentrations of 1 and comonomer B (Figure 3B). Importantly, the instantaneous molar fraction of $\mathbf{1}$ incorporated in the copolymer (denoted hereafter as $F_{1}$ ) remained identical to $f_{1}^{0}$ throughout the copolymerization (Figure S3). Correspondingly, the final copolymer composition, $F_{1}^{(e n d)}$, when the reaction reached the end point, was also identical to $f_{1}^{0}$ (Table 1 , entry 1 ). These results suggested that the reactivities of the two comonomers are highly similar in chain propagation. To determine the reactivity ratios of the copolymerization, the compositional data of 1 and $B$ throughout the copolymerization was fitted to the Beckingham-Sanoja-Lynd (BSL) integrated model reported by Lynd et al. ${ }^{60}$

$$
\begin{aligned}
& \operatorname{conv} .=1-f_{1}^{0}\left[\frac{1(t)}{1(0)}\right]-\left(1-f_{1}^{0}\right)\left[\frac{1(t)}{1(0)}\right]^{r_{B}} \\
& \operatorname{conv} .=1-f_{1}^{0}\left[\frac{B(t)}{B(0)}\right]^{r_{1}}-\left(1-f_{1}^{0}\right)\left[\frac{B(t)}{B(0)}\right]
\end{aligned}
$$

where $r_{1}$ and $r_{B}$ are reactivity ratios of $\mathbf{1}$ and comonomer $\mathrm{B}$. It is noteworthy that although the BSL model is derived for ideal copolymerization where $r_{A} \times r_{B}=1$, such as ionic or metalcatalyzed copolymerization systems, we reasoned that the copolymerization of the macrocyclic allylic sulfone and acrylic monomers is a close approximation of the ideal copolymerization, because the allylic sulfone motif was designed such that the propagating secondary alkyl radical formed after the radical cascade process is structurally similar to the propagating radical of polyacrylates. ${ }^{61}$ Independent fitting of the polymer compositional data to Eq 2 and Eq 3 supported this rationale, as the derived reactivity ratios of the comonomers were $r_{1}=1.07$ and $r_{B}=0.94$, with $r_{1} \times r_{B}=1.006$ (Figure $3 \mathrm{C}$ ). These results suggest that the copolymerization is truly random and that it is indeed highly analogous to an ideal copolymerization in which the product of the two reactivity ratios equals 1 . The reactivity ratios of 1 and MA in the entire range of monomer feed compositions $\left(f_{1}^{0}=0-1\right)$ remained close to unity (Table 1, entries 1-6 \& Figure 3D \& Figure S4-13). Furthermore, copolymerization of 1 and other acrylic comonomers, including tert-butyl acrylate (tBA), benzyl acrylate $(\mathrm{BnA})$, and $N, N$-dimethylacrylamide (DMA), at $f_{1}^{0}=0.09$ all exhibited excellent control over the polymerization and nearunity reactivity ratios, suggesting that this method is generally applicable to a wide range of acrylates and acrylamides (Table 1, entries 7-9 \& Figure S14-19). 
Table 1. Photocontrolled rROCCP of 1 and various acrylates or acrylamides

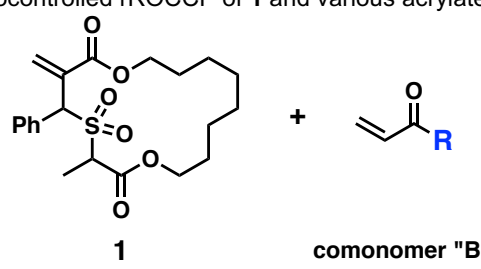

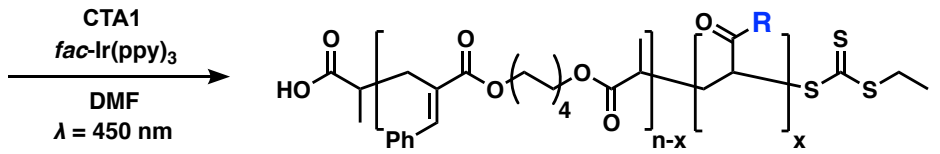
comonomer "B"

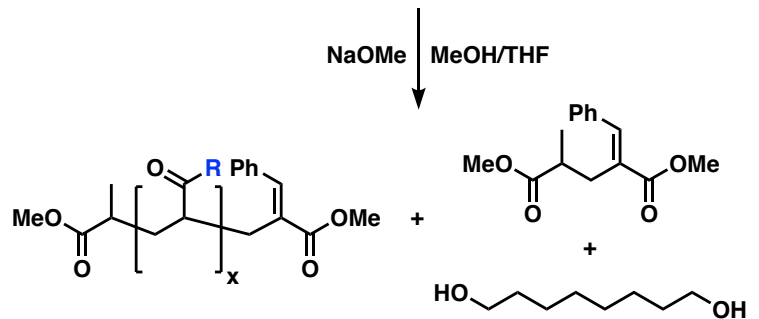

\begin{tabular}{|c|c|c|c|c|c|c|c|c|c|c|}
\hline Entry $^{a}$ & B & $f_{1}^{0}$ & $r_{1}$ & $r_{B}$ & Conv. ${ }^{b}$ & $\begin{array}{c}M_{\mathrm{n}}^{(\mathrm{SEC})} \\
(\mathrm{kg} / \mathrm{mol})^{c}\end{array}$ & $\oplus^{c}$ & $F_{1}^{(e n d)_{b}}$ & $\begin{array}{c}\text { Degraded } \\
M_{\mathrm{n}}(\mathrm{SEC}) \\
(\mathrm{kg} / \mathrm{mol})^{c}\end{array}$ & $\begin{array}{c}\text { Degraded } \\
\theta^{c}\end{array}$ \\
\hline 2 & MA & 0.09 & 1.05 & 0.95 & $82 \%$ & 21.7 & 1.27 & 0.10 & 1.3 & 1.33 \\
\hline 4 & MA & 0.50 & 1.06 & 0.94 & $70 \%$ & 9.3 & 1.12 & 0.51 & 0.6 & 1.12 \\
\hline 5 & MA & 0.67 & 1.04 & 0.96 & $75 \%$ & 7.7 & 1.18 & 0.68 & 0.5 & 1.07 \\
\hline 6 & MA & 0.80 & 1.04 & 0.97 & $61 \%$ & 6.8 & 1.17 & 0.80 & 0.5 & 1.06 \\
\hline 7 & $t \mathrm{BA}$ & 0.09 & 1.04 & 0.96 & $85 \%$ & 39.0 & 1.29 & 0.09 & 2.6 & 1.34 \\
\hline 8 & $\mathrm{BnA}$ & 0.09 & 0.84 & 1.19 & $89 \%$ & 22.1 & 1.38 & 0.08 & 2.9 & 1.35 \\
\hline 9 & DMA & 0.09 & 1.03 & 0.97 & $75 \%$ & 16.1 & 1.21 & 0.11 & 1.8 & 1.42 \\
\hline
\end{tabular}

${ }^{a}$ Experimental conditions: $18 \mathrm{~W}$ blue LED light $\left(\lambda_{\max }=450 \mathrm{~nm}\right), 25^{\circ} \mathrm{C}$ under argon in a sealed vial for $8 \mathrm{~h} .{ }^{b}$ Monomer conversion and $F_{1}^{(\text {end })}$ were determined by ${ }^{1} \mathrm{H}$ NMR spectroscopy. ${ }^{c} M_{\mathrm{n}}$ and $\boxminus$ were determined by SEC analysis calibrated to polystyrene standards.

To investigate how degradability was influenced by the composition and distribution of degradable building blocks in copolymers, copolymers were treated with sodium methoxide to cleave the main-chain esters. SEC analysis of the degradation of the copolymer P-(1-co-MA) prepared by the photocontrolled $\operatorname{rROCCP}\left(F_{1}^{(e n d)}=0.10, M_{\mathrm{n}}^{(\mathrm{SEC})}=19.2 \mathrm{~kg} / \mathrm{mol}\right.$, and $\left.\oplus=1.27\right)$ exhibited a dramatic molecular weight reduction after degradation, resulting in oligomers with $M_{\mathrm{n}}{ }^{(\mathrm{SEC})}$ of $1.3 \mathrm{~kg} / \mathrm{mol}$ and $\Theta$ of 1.33 (Table 2, entry 2 \& Figure 4A). In contrast, degradation of the copolymer with a similar overall composition $\left(F_{1}^{(\text {end })}=0.08\right.$ $M_{\mathrm{n}}{ }^{(\mathrm{SEC})}=16.4 \mathrm{~kg} / \mathrm{mol}$, and $\left.\Theta=1.52\right)$ generated by the thermallyinitiated copolymerization produced frag

ments with higher $M_{\mathrm{n}}$ and $\doteq\left(M_{\mathrm{n}}{ }^{(\mathrm{SEC})}=7.3 \mathrm{~kg} / \mathrm{mol}, \doteq=1.98\right)$ (Figure 4A). Furthermore, the degradation of copolymers with different comonomer compositions generated by the photocontrolled rROCCP consistently produced fragments with low $M_{n}$ and narrow molecular weight distributions (Table 2). These results indicated that while the thermally initiated copolymerization yielded a gradient copolymer that could only be partially degraded, copolymers generated by the photocontrolled rROCCP possessed even and tunable distributions of main-chain degradable functionalities and could be degraded efficiently into low molecular weight fragments.
The thermal properties of copolymers were further evaluated by thermogravimetry (TGA) and differential scanning calorimetry (DSC) analyses. P-(1-co-MA) with main-chain degradable functionalities at different copolymer compositions established similar thermal stability comparable to polymethylacrylate with $5 \%$ weight loss decomposition temperature $\left(T_{d}\right)$ between $363-368{ }^{\circ} \mathrm{C}$ (Figure 4B). Furthermore, glass transition temperature $\left(T_{\mathrm{g}}\right)$ of $\mathbf{P}$ (1-co-MA) can be fine-tuned by the initial comonomer feed composition in copolymerization, highlighting the potential utility of this method in generating degradable vinyl polymers with tailormade material properties (Figure 4C).

\section{Understanding the Unusual Kinetic Behavior}

Our studies have shown that while the PET-RAFT homopolymerization and copolymerization (Figure S3 \& S20-26) involving macrocyclic allylic sulfones deviated from the first-order kinetics, the polymerization remained well-controlled. This phenomenon was in stark contrast to traditional controlled polymerization in which deviation of first-order kinetics is usually a sign of loss of control, suggesting an unusual kinetic behavior that warranted further investigation. We suspected that the in situ generated $\mathrm{SO}_{2}$ in the radical cascade polymerization affected the reaction kinetics. ${ }^{62-64}$ 
A

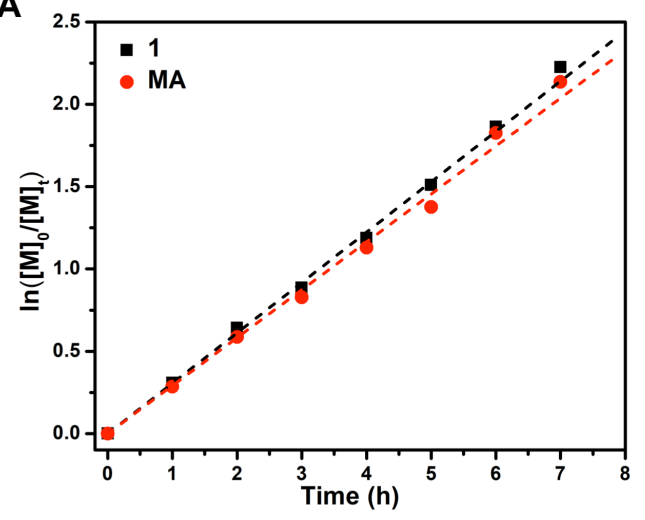

C

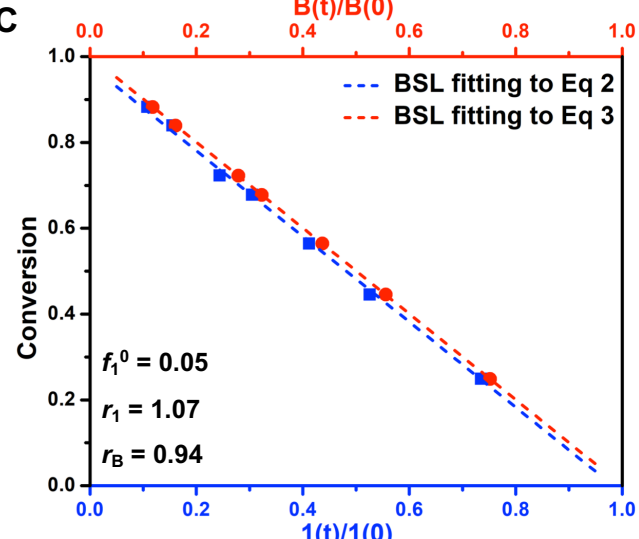

B

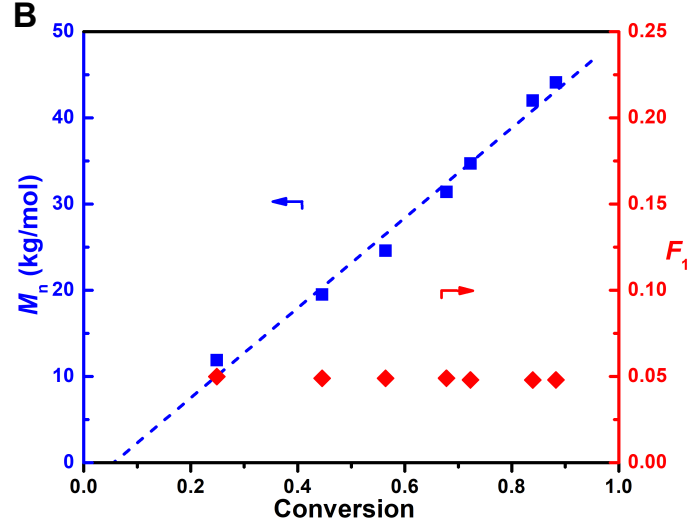

D

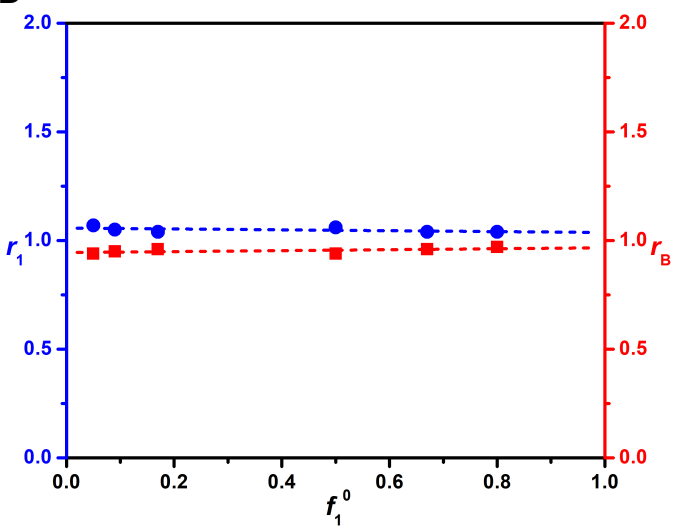

Figure 3. Photocontrolled $\mathrm{rROCCP}$ of macrocyclic allylic sulfone and various acrylates and acrylamides is truly random. A) Kinetic plots of In([M] $/[\mathrm{M}] \mathrm{t})$ versus reaction time of both comonomers. B) Plots of $M_{n}$ and incorporation of $\mathbf{1}\left(F_{1}\right)$ as a function of total conversion. C) The plot of total conversion with respect to $[1(t)] /[1(0)]$ or $[B(t)] /[B(0)]$ is fitted to Eq 2 and $E q 3$ of the $B S L$ model independently to derive the reactivity ratios. D) The reactivity ratios of 1 and $M A$ in the photocontrolled rROCCP remained close to unity in a broad range of monomer feed compositions.

To investigate this hypothesis, Density Functional Theory (DFT) calculations were carried out using the M06-2X/6$311++G(d, p) / / B 3 L Y P / 6-31 G(d)$ method in conjunction with the Solvation Model based on Density (SMD) simulating the effect from DMF to compute a plausible potential energy surface of the cascade process in the polymerization of macrocyclic allylic sulfones (Figure $5 \mathrm{~B}$ ). ${ }^{65}$ Our calculation showed that the $\alpha$ scission $/ \mathrm{SO}_{2}$ extrusion step $\left(\mathrm{G}_{2}\right.$ to $\left.\mathrm{G}_{3}\right)$ has a low energy barrier of $5.9 \mathrm{kcal} / \mathrm{mol}$, and that this transformation is exergonic by 2.8 $\mathrm{kcal} / \mathrm{mol}$. The low activation energy and relatively small change in Gibbs free energy indicates that this step is likely reversible. The DFT calculations also suggest that $\mathrm{G}_{3}$, with the lowest energy in the whole cascade process, exists at a high enough concentration during steady-state conditions, making it a plausible intermediate for chain propagation (Figure S27). Compared to chain propagation $\left(\mathrm{G}_{3}-\mathrm{TS}_{4}-\mathrm{G}_{4}\right.$, with an energy barrier of $\left.20.7 \mathrm{kcal} / \mathrm{mol}\right)$, two alternative reaction pathways of $\mathrm{G}_{3}$ with lower energy barriers are the reversible addition by the CTA $\left(\mathrm{G}_{3}-\mathrm{TS}_{5}-\mathrm{G}_{5}\right.$, with an energy barrier of $12.0 \mathrm{kcal} / \mathrm{mol})$ or $\mathrm{SO}_{2}\left(\mathrm{G}_{3}-\mathrm{TS}_{3}-\mathrm{G}_{2}\right.$, with an energy barrier of $8.7 \mathrm{kcal} / \mathrm{mol}$ ). While the former serves as the reversible deactivation of the chain propagation to achieve controlled polymerization, the latter is a reverse reaction of the $\alpha$ scission $/ \mathrm{SO}_{2}$ extrusion step and regenerates the sulfonyl radical $\mathrm{G}_{2}$. Because of a high energy barrier of $19.7 \mathrm{kcal} / \mathrm{mol}$ and being endergonic by $9.8 \mathrm{kcal} / \mathrm{mol}$, chain propagation of $\mathrm{G}_{2}$ by the monomer $\left(\mathrm{G}_{2}-\mathrm{TS}_{6}-\mathrm{G}_{6}\right)$ is prohibited thermodynamically and kinetically. These results indicate that excess $\mathrm{SO}_{2}$ in the reaction could indeed recombine with the propagating alkyl radical to regenerate the sulfonyl radical and inhibit chain propagation.
To provide further evidence of the presence and accumulation of sulfonyl radical over the course of reaction, we employed electron paramagnetic resonance (EPR) to monitor the evolution of radical species in the reaction in situ (Figure 5C). In the early stage (initial two hours) of the reaction, the EPR spectrum only consisted of signals corresponding to the alkyl radical $\mathbf{a}\left(g_{0}=2.004\right)$ and the degenerative intermediate $\mathbf{b}\left(g_{0}=\right.$ 2.009) (Spectrum I, Figure 5C). The $g$-values of the peaks and patterns of the spectrum are consistent with the radical species generated in the radical polymerization of MA. The EPR spectrum gradually evolved as the polymerization proceeded. In the late stage (after five hours) of the reaction, a new peak c with a $g$ value of 2.014 appeared in the EPR spectrum (Spectrum II, Figure $5 \mathrm{C}$ ), which is consistent with the $g$-value of the sulfonyl radical reported in literature. ${ }^{66}$ Furthermore, simulated EPR spectra (dotted lines) based on the absence and presence of the sulfonyl radical in the reaction perfectly fit the experimental data as shown in Spectrum I and II, respectively, confirming the proposed assignments. Notably, Spectrum II is also consistent with Spectrum III obtained after the exogenous $\mathrm{SO}_{2}$ gas was introduced to the system at the early stage of the reaction (Figure $5 \mathrm{C})$. Collectively, the DFT calculations and EPR analyses are consistent with the observed kinetic results, confirming that $\mathrm{G} 2$ (peak c in Figure 5C), G3 (peak a in Figure 5C), and G5 (peak b in Figure $5 \mathrm{C}$ ) are long-lived radical intermediates in the polymerization of macrocyclic allylic sulfones, and that the concentration of $\mathrm{SO}_{2}$ could have a significant effect on the direction of the reaction. 
A

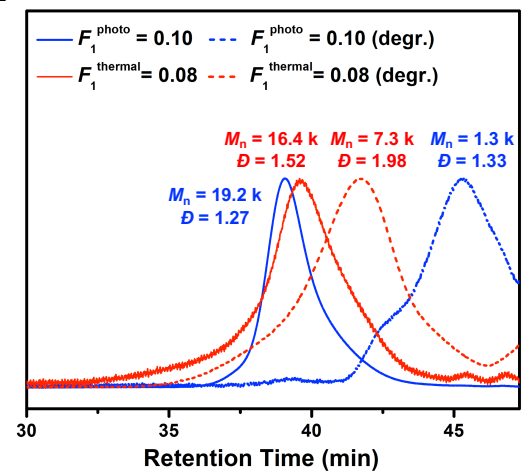

B

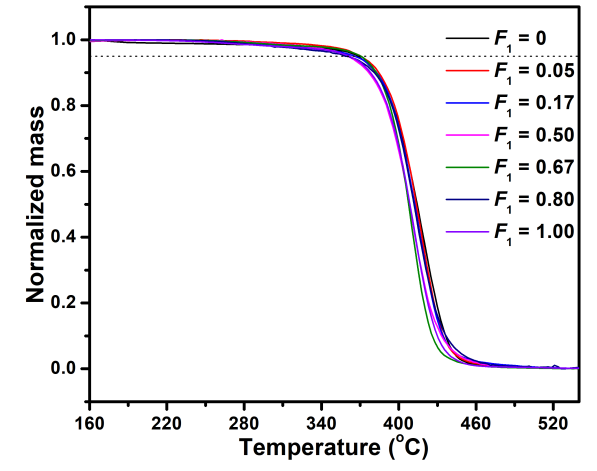

C

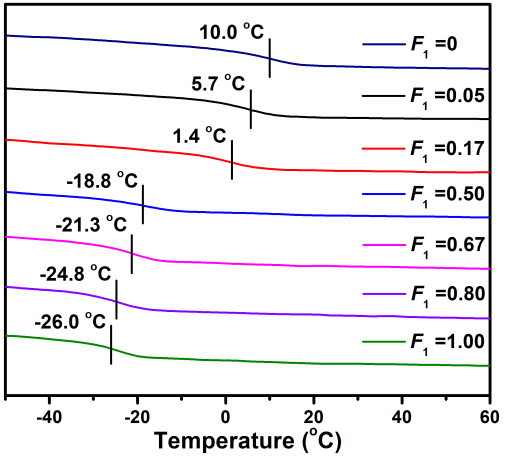

Figure 4. Material properties of the truly random degradable vinyl copolymers prepared by the photocontrolled rROCCP. A) Degradation of P-(1-co-MA) generated by the photocontrolled copolymerization $\left(F_{1}^{(e n d)}=0.10\right)$ and the thermally-initiated radical copolymerization $\left(F_{1}^{(e n d)}=0.08\right)$ respectively. B) The $T_{\mathrm{d}}$ of the copolymers P-(1-co-MA) with different compositions demonstrated similar thermal stability with PMA. C) The $T_{\mathrm{g}}$ of the copolymers P-(1-co-MA) could be fine-tuned by the initial comonomer feed composition.

\section{Overcoming the Propagation Inhibition by $\mathrm{SO}_{2}$.}

Based on DFT calculations, we reason that the propagation inhibition by the in situ generated $\mathrm{SO}_{2}$ may be reversible, given the low energy barrier of the process. This reversibility implies that the extrusion of $\mathrm{SO}_{2}$ and the formation of the alkyl radical are favored at low $\mathrm{SO}_{2}$ concentrations, whereas the recombination of $\mathrm{SO}_{2}$ and the formation of the sulfonyl radical are favored at high $\mathrm{SO}_{2}$ concentrations. Therefore, the propagation inhibition could be alleviated by removing $\mathrm{SO}_{2}$ from the reaction. Indeed, we found that sparging the reaction mixture with argon steadily increased the rate of the PET-RAFT homopolymerization of 1 in the late stage of the reaction at $25^{\circ} \mathrm{C}$ (Figure S28). In fact, both the $\mathrm{SO}_{2}$ inhibition and reactivation of chain propagation by argon sparging were reversible and the polymerization could be switched "on"/"off" by alternating the exogenous $\mathrm{SO}_{2}$ and argon introduced into the reaction vessel (Figure S29-S30). Similarly, the propagation inhibition was also alleviated in the copolymerization of 1 and $\mathrm{BnA}\left(f_{1}^{0}=0.09\right)$ by argon sparging at $25{ }^{\circ} \mathrm{C}$ (Figure S31). Additionally, increasing the reaction temperature to $50{ }^{\circ} \mathrm{C}$ was also found to improve the rate of the homopolymerization of $\mathbf{1}$ in the late stage (Figure S32-S33). Combining the argon sparging and the temperature elevation to $50{ }^{\circ} \mathrm{C}$ proved to further improve the reaction kinetics of the homopolymerization of $\mathbf{1}$, allowing it to remain pseudo first-order throughout the reaction (Figure 6A). The rate of copolymerization of 1 and MA was also improved when the reaction temperature was elevated to $50^{\circ} \mathrm{C}$ (Figure S34), but a modest deviation of the comonomer reactivity ratios from unity was observed (Figure S35). We reasoned that an alternative strategy to reduce the propagation inhibition by $\mathrm{SO}_{2}$ was to switch the solvent from DMF to dioxane, in which $\mathrm{SO}_{2}$ has lower solubility (Figure S36). Encouragingly, we found that the kinetics of copolymerization of 1 and $\mathrm{BnA}$ at $25{ }^{\circ} \mathrm{C}$ remained pseudo first-order throughout the reaction when dioxane was used as the solvent (Figure 6B).

A

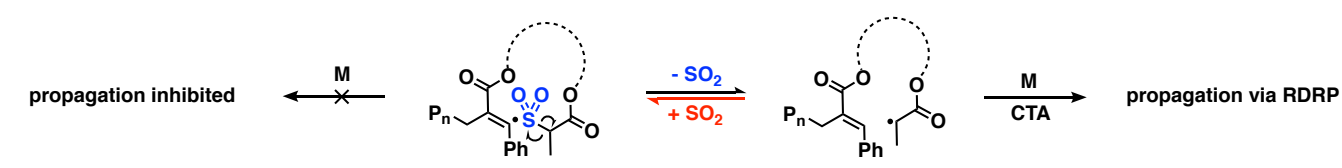

B

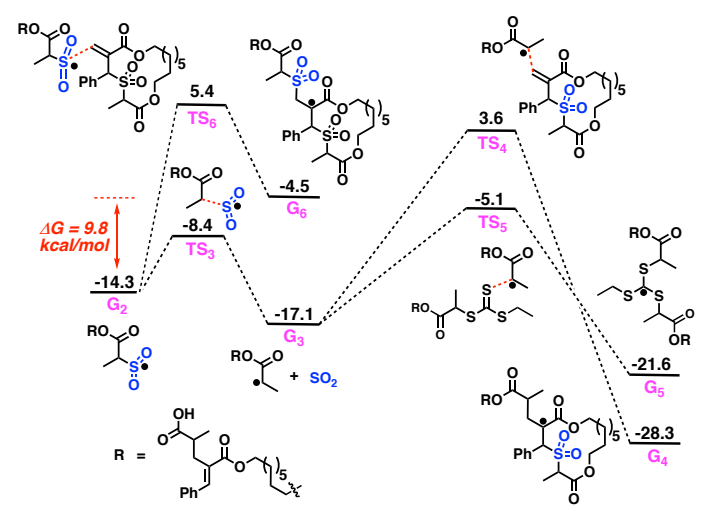

C

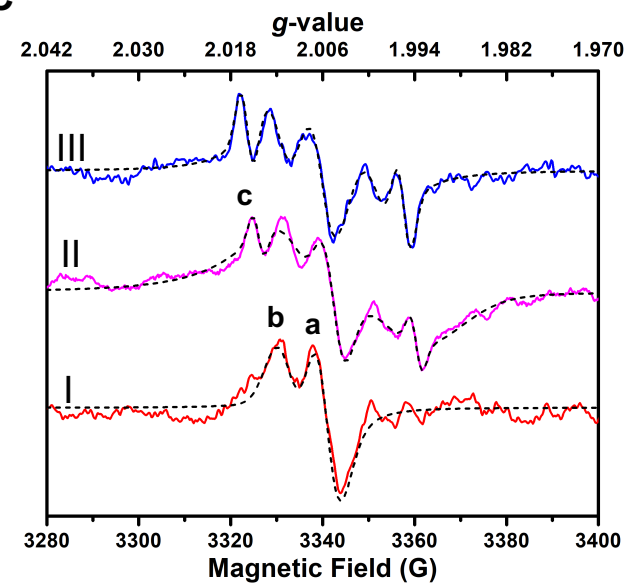

Figure 5. Mechanistic investigation of the cascade process of the polymerization of macrocyclic allylic sulfones. A) $\mathrm{SO}_{2}$ is hypothesized to inhibit chain propagation by recombining with the propagating radical. M denotes monomers. B) DFT calculations. C) EPR studies of the polymerization of macrocyclic allylic sulfones. The experimental results are shown as solid lines. The simulated EPR spectra based on the hypothesized composition of the reaction mixture at different stages of the reaction are shown as dotted lines. The experimental EPR spectra are well aligned with the simulated ones. Spectrum I: Early stage of polymerization (first two hours). Spectrum II: Late stage of polymerization (after five hours). Spectrum III: Injection of exogenous $\mathrm{SO}_{2}$ at early stage of polymerization. 
A

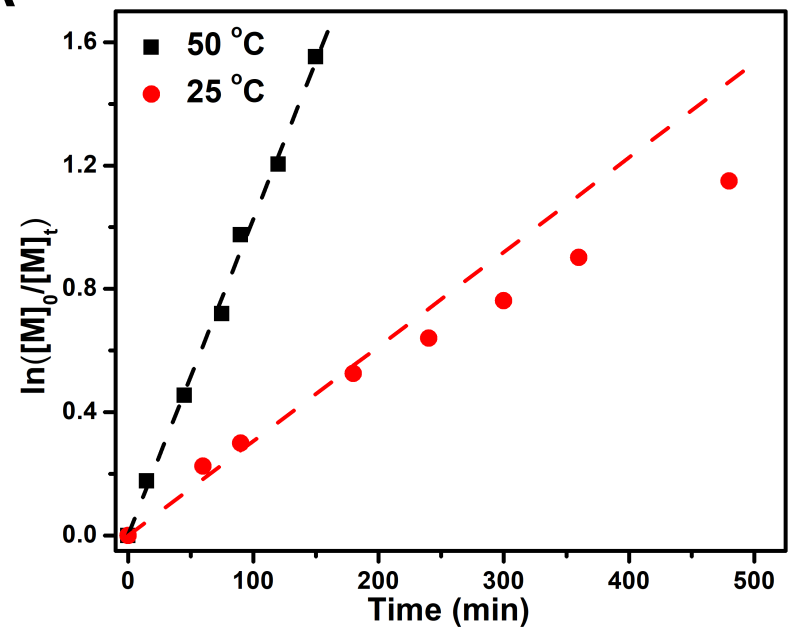

B

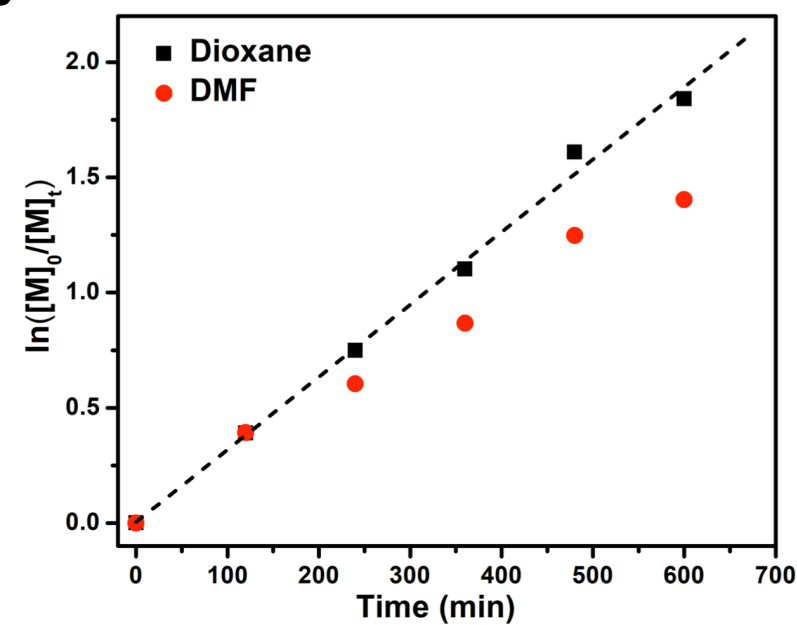

Figure 6. Inhibition of propagation by $\mathrm{SO}_{2}$ is reversible. A) Pseudo first-orde kinetics was achieved in the PET-RAFT homopolymerization of 1 by elevating temperature to $50^{\circ} \mathrm{C}$ plus argon sparging. B) Photocontrolled rROCCP of 1 and $\mathrm{BnA}$ at $f_{1}^{0}=0.09$ in dioxane remained pseudo first-order throughout the reaction.

\section{Conclusion}

A novel approach to the truly random degradable vinyl polymers with tunable main-chain composition via photocontrolled radical ring-opening cascade copolymerization ( $\mathrm{rROCCP})$ is presented in this article. Compared to existing rROP systems, the photocontrolled rROCCP enabled the synthesis of truly random degradable vinyl copolymers with evenly distributed, tunable composition of the main-chain labile groups at ambient temperature. Computational and EPR analyses revealed that the reversible inhibition of the chain propagation by in situ generated $\mathrm{SO}_{2}$ caused an unusual kinetic behavior that showed a deviation from first-order kinetics in the late stage of the reaction. Removal of $\mathrm{SO}_{2}$ was found to reverse the inhibition of the chain propagation and improve the reaction kinetics in both the homopolymerization and the copolymerization involving macrocyclic allylic sulfones. Taken together, excellent control and favorable comonomer reactivity ratios make photocontrolled $\mathrm{rROCCP}$ a powerful strategy for the preparation of truly random degradable vinyl copolymers with tunable main-chain compositions for a wide range of applications. In addition, the mechanistic insights into the reversible inhibition of chain propagation by $\mathrm{SO}_{2}$ shed light on using chemical cues to control radical chain-growth cascade polymerization systems.

\section{Acknowledgements}

We thank Marek Domin, Jiangwei Liu, Matthew Thompson, Miao Qi, Gavin Giardino, Jingsong Yuan, Lianqian Wu, Cangjie Yang, Hanchu Huang, and Jeff Byers for characterization assistance and helpful discussions. The research is primarily supported by a CAREER award from the National Science Foundation (CHE1944512) to J.N. We also acknowledge the partial support provided by the Arnold and Mabel Beckman Foundation through a Beckman Young Investigator Award to J.N. and the American Chemical Society through a Petroleum Research Fund Doctoral New Investigator Award (60747DNI7) to J.N.

\section{Conflict of interest}

A provisional patent based on this work has been filed.

Keywords: photocontrolled polymerization $\cdot$ cascade polymerization • degradable polymer • truly random copolymer • reaction mechanism

[1] R. Geyer, J. R. Jambeck, K. L. Law, Sci. Adv. 2017, 3, e1700782.

[2] M. E. Seeley, B. Song, R. Passie, R. C. Hale, Nat. Commun. 2020, 11, 2372.

[3] V. Delplace, J. Nicolas, Nat. Chem. 2015, 7, 771-784.

[4] M. Mohadjer Beromi, C. R. Kennedy, J. M. Younker, A. E. Carpenter, S. J. Mattler, J. A. Throckmorton, P. J. Chirik, Nat. Chem. 2021,13, 156-162.

[5] W. J. Bailey, Polym. J. 1985, 17, 85-95.

[6] A. Tardy, J. Nicolas, D. Gigmes, C. Lefay, Y. Guillaneuf, Chem. Rev. 2017, 117, 1319-1406.

[7] T. Pesenti, J. Nicolas, ACS Macro Lett. 2020, 9, 1812-1835.

[8] N. Corrigan, K. Jung, G. Moad, C. J. Hawker, K. Matyjaszewski, C. Boyer, Prog. Polym. Sci. 2020, 111, 101311.

[9] W. J. Bailey, Z. Ni, S.-R. Wu, J. Polym. Sci., Polym. Chem. Ed. 1982, 20, 3021-3030.

[10] G. G. Hedir, C. A. Bell, N. S. leong, E. Chapman, I. R. Collins, R. K. O'Reilly, A. P. Dove, Macromolecules 2014, 47, 2847-2852.

[11] G. G. Hedir, C. A. Bell, R. K. O'Reilly, A. P. Dove, Biomacromolecules 2015, 16, 2049-2058.

[12] C. A. Bell, G. G. Hedir, R. K. O'Reilly, A. P. Dove, Polym. Chem. 2015, 6, 7447-7454.

[13] G. G. Hedir, M. C. Arno, M. Langlais, J. T. Husband, R. K. O'Reilly, A. P. Dove, Angew. Chem. Int. Ed. 2017, 56, 9178-9182.

[14] G. Hedir, C. Stubbs, P. Aston, A. P. Dove, M. I. Gibson, ACS Macro Lett. 2017, 6, 1404-1408.

[15] V. Delplace, E. Guegain, S. Harrisson, D. Gigmes, Y. Guillaneuf, J. Nicolas, Chem. Commun. 2015, 51, 12847-12850.

[16] J. Tran, E. Guegain, N. Ibrahim, S. Harrisson, J. Nicolas, Polym. Chem. 2016, 7, 4427-4435.

[17] A. Tardy, J.-C. Honore, J. Tran, D. Siri, V. Delplace, I. Bataille, D. Letourneur, J. Perrier, C. Nicoletti, M. Maresca, C. Lefay, D. Gigmes, J. Nicolas, Y. Guillaneuf, Angew. Chem. Int. Ed. 2017, 56, 16515-16520.

[18] E. Guegain, J.-P. Michel, T. Boissenot, J. Nicolas, Macromolecules 2018, 51, 724-736. 
[19] E. Guegain, J. Tran, Q. Deguettes, J. Nicolas, Chem. Sci. 2018, 9, 82918306.

[20] E. Guegain, C. Zhu, E. Giovanardi, J. Nicolas, Macromolecules 2019, 52, 3612-3624.

[21] M. R. Hill, E. Guegain, J. Tran, C. A. Figg, A. C. Turner, J. Nicolas, B. S Sumerlin, ACS Macro Lett. 2017, 6, 1071-1077.

[22] M. R. Hill, T. Kubo, S. L. Goodrich, C. A. Figg, B. S. Sumerlin, Macromolecules 2018, 51, 5079-5084.

[23] A. Tardy, N. Gil, C. M. Plummer, D. Siri, D. Gigmes, C. Lefay, Y Guillaneuf, Angew. Chem. Int. Ed. 2020, 59, 14517-14526.

[24] R. A. Evans, G. Moad, E. Rizzardo, S. H. Thang, Macromolecules 1994 27, 7935-7937.

[25] J. M. J. Paulusse, R. J. Amir, R. A. Evans, C. J. Hawker, J. Am. Chem. Soc. 2009, 131, 9805-9812.

[26] L. P. D. Ratcliffe, C. Couchon, S. P. Armes, J. M. J. Paulusse Biomacromolecules 2016, 17, 2277-2283.

[27] J. Du, B. Choi, Y. Liu, A. Feng, S. H. Thang, Polym. Chem. 2019, 10, 1291-1298.

[28] R. A. Smith, G. Fu, O. McAteer, M. Xu, W. R. Gutekunst, J. Am. Chem. Soc. 2019, 141, 1446-1451.

[29] N. M. Bingham, P. J. Roth, Chem. Commun. 2019, 55, 55-58.

[30] M. P. Spick, N. M. Bingham, Y. Li, J. de Jesus, C. Costa, M. J. Bailey, P. J. Roth, Macromolecules 2020, 53, 539-547.

[31] H. Huang, B. Sun, Y. Huang, J. Niu, J. Am. Chem. Soc. 2018, 140, 10402-10406.

[32] B. Quiclet-Sire, S. Z. Zard, J. Am. Chem. Soc. 1996, 118, 1209-1210.

[33] B. P. Fors, C. J. Hawker, Angew. Chem. Int. Ed. 2012, 51, 8850-8853.

[34] H. Zhou, J. A. Johnson, Angew. Chem. Int. Ed. 2013, 52, 2235-2238.

[35] A. Anastasaki, V. Nikolaou, Q. Zhang, J. Burns, S. R. Samanta, C Waldron, A. J. Haddleton, R. McHale, D. Fox, V. Percec, P. Wilson, D. M. Haddleton, J. Am. Chem. Soc. 2014, 136, 1141-1149.

[36] N. J. Treat, H. Sprafke, J. W. Kramer, P. G. Clark, B. E. Barton, J. Read de Alaniz, B. P. Fors, C. J. Hawker, J. Am. Chem. Soc. 2014, 136, 1609616101.

[37] M. Chen, M. Zhong, J. A. Johnson, Chem. Rev 2016, 116, 10167-10211.

[38] J. C. Theriot, C.-H. Lim, H. Yang, M. D. Ryan, C. B. Musgrave, G. M. Miyake, Science 2016, 352, 1082-1086.

[39] E. E. Stache, V. Kottisch, B. P. Fors, J. Am. Chem. Soc. 2020, 142, 4581 4585.

[40] K. Jiang, S. Han, M. Ma, L. Zhang, Y. Zhao, M. Chen, J. Am. Chem. Soc. 2020, 142, 7108-7115.

[41] Q. Quan, M. Ma, Z. Wang, Y. Gu, M. Chen, Angew. Chem. Int. Ed. 2021 60, 2-11.

[42] A. J. Perkowski, W. You, D. A. Nicewicz, J. Am. Chem. Soc. 2015, 137, 7580-7583.

[43] M. S. Messina, J. C. Axtell, Y. Wang, P. Chong, A. I. Wixtrom, K. O. Kirlikovali, B. M. Upton, B. M. Hunter, O. S. Shafaat, S. I. Khan, J. R. Winkler, H. B. Gray, A. N. Alexandrova, H. D. Maynard, A. M. Spokoyny, J. Am. Chem. Soc. 2016, 138, 6952-6955.

[44] V. Kottisch, Q. Michaudel, B. P. Fors, J. Am. Chem. Soc. 2016, 138 15535-15538

[45] Q. Michaudel, T. Chauvire, V. Kottisch, M. J. Supej, K. J. Stawiasz, L. Shen, W. R. Zipfel, H. D. Abruna, J. H. Freed, B. P. Fors, J. Am. Chem. Soc. 2017, 139, 15530-15538.

[46] X. Zhang, Y. Jiang, Q. Ma, S. Hu, S. Liao, J. Am. Chem. Soc. 2021, 143, 6357-6362.

[47] K. A. Ogawa, A. E. Goetz, A. J. Boydston, J. Am. Chem. Soc. 2015, 137, 1400-1403.

[48] A. E. Goetz, A. J. Boydston, J. Am. Chem. Soc. 2015, 137, 7572-7575.

[49] T. Krappitz, K. Jovic, F. Feist, H. Frisch, V. P. Rigoglioso, J. P. Blinco, A. J. Boydston, C. Barner-Kowollik, J. Am. Chem. Soc. 2019, 141, 1660516609.

[50] H. Lai, J. Zhang, F. Xing, P. Xiao, Chem. Soc. Rev., 2020, 49, 1867-1886.

[51] J. Xu, K. Jung, A. Atme, S. Shanmugam, C. Boyer, J. Am. Chem. Soc. 2014, 136, 5508-5519.

[52] J. Xu, K. Jung, N. A. Corrigan, C. Boyer, Chem. Sci. 2014, 5, 3568-3575.

[53] J. Xu, S. Shanmugam, H. T. Duong, C. Boyer, Polym. Chem. 2015, 6 , 5615-5624.

[54] S. Shanmugam, J. Xu, C. Boyer, J. Am. Chem. Soc. 2015, 137, 91749185.

[55] N. Corrigan, S. Shanmugam, J. Xu, C. Boyer, Chem. Soc. Rev. 2016, 45 , 6165-6212.

[56] N. Li, D. Ding, X. Pan, Z. Zhang, J. Zhu, C. Boyer, X. Zhu, Polym. Chem. 2017, 8, 6024-6027

[57] G. I. Perterson, T.-L. Choi, Chem. Sci. 2020, 11, 4843-4854.

[58] J. Yuan, W. Wang, Z. Zhou, J. Niu, Macromolecules 2020, 53, 5655-5673.

[59] H. Huang, W. Wang, Z. Zhou, B. Sun, M. An, F. Haeffner, J. Niu, J. Am. Chem. Soc. 2019, 141, 12493-12497.

[60] N. A. Lynd, R. C. Ferrier, B. S. Beckingham, Macromolecules 2019, 52 2277-2285.
[61] B. S. Beckingham, G. E. Sanoja, N. A. Lynd, Macromolecules 2015, 48, $6922-6930$

[62] Z. Florjanczyk, Prog. Polym. Sci. 1991, 16, 509-560.

[63] G. Qiu, K. Zhou, L. Gao, J. Wu, Org. Chem. Front. 2018, 5, 691-705

[64] K. Hofman, N.-W. Liu, G. Manolikakes, Chem. Eur. J. 2018, 24, 1185211863.

[65] A. V. Marenich, C. J. Cramer, D. G. Truhlar, J. Phys. Chem. B 2009, 113, 6378-6396.

[66] J. S. Hwang, C. P. Tsonis, J. Polym. Sci., Part A: Polym. Chem. 1993, $31,1417-142$. 
